\title{
Reimagining City Identities in Globalisation: A Constructivist Study
}

\section{on City Paradiplomacy}

\section{Ario Bimo Utomo}

Universitas Pembangunan Nasional "Veteran” Jawa Timur, Indonesia ariobimo.utomo@gmail.com

The study of diplomacy has encountered a new turn when the concept of parallel diplomacy, or paradiplomacy, was introduced to the mainstream. The concept itself can be defined as the international agency of sub-national political entities. The logic behind this is that globalisation has given a channel for the local entities to further their interests amidst the prevailing statecentric international system. In the International Relations scholarship, this issue can be viewed through three lenses: realist, liberalist, and constructivist. This article will use constructivism whose idea argues that paradiplomacy contains identity-seeking undertones beneath, where subnational entities can reimagine their positions in globalisation. The constructivist lens offers more advantage in seeing paradiplomacy beyond activities which are mainly driven by free-trade. This paper attempts to use the constructivist lens of paradiplomacy in exploring how cities can construct their identities in globalisation. There has been a quite extensive literature on constructivist perspective on paradiplomacy, yet many of them are focused on secessionist case studies instead of cities as regular sub-national units which pose no threat to their host states. This article argues that identity creation in city paradiplomacy is possible and particularly essential to cities located in developing countries seeking partnerships with the more developed regions. In doing the research, the author utilises secondary sources through the existing studies on paradiplomacy and city identity in globalisation to keep up with the current state of the art.

Keywords: paradiplomacy; city; constructivism; globalisation.

\section{Introduction}

In the international politics, there is a conventional assumption that states remain the most influential polity entity. States became the most significant entities since the Westphalia Treaty in 1648 gave birth to the concept of sovereignty for the nation-state. From the realist perspective, the state's position is difficult to match because of the culture of an anarchic global system. This means that there is no higher entity that regulates how countries must behave in international politics.
However, this notion has been slowly changing with the advent of globalisation. In this case, globalisation has become a process that increases the interactions of goods, services, and information so that national borders seem to erode. A number of researchers (Keohane and Nye 1977, Bell 1999, and Giddens 2002) have offered the idea that slowly, states are no longer considered the most important entity in international relations. This certainly makes sense, given the fundamental differences between the logic of the state and the logic 
of globalisation. On one hand, the state logic operates within a hierarchical framework that places order above all, besides that, it has some jurisdictional boundaries in the form of clearly defined territories. On the other hand, globalisation works with an egalitarian and cross-border logic. Facing the current of increasingly rapid globalisation, states have become too big to deal with small problems, while at the same time it is too small to deal with big problems.

Giddens (2002) through Runaway World argues that globalisation has changed many aspects of our lives. Giddens begins by summarising two major positions in looking at globalisation, namely skeptics and radicals. Skeptics assume that globalisation is not a new issue. He argues that these people see that globalisation is nothing more than just a nonsense. Skeptics do not see any significant change in the global economy, because this camp argue that the majority of countries have been involved in foreign trades even before the globalisation became a new concept. On another spectrum, there are radicals who think that globalisation is not only real - it is felt in various sectors of society. The radical argument holds that the global economy is far more open than in the past, and national borders seem to have no significant meaning. Not only that, radicals argue that the sovereignty of countries has eroded and the era of the nation-state has reached its twilight.

In his article, Giddens takes an affirmative position towards the radical camp. At the same page, he continues a premise that globalisation has given rise to three directions of strength. Traditionally, we have understood that globalisation has an upward force, that is, "pulling" what was once a local issue into a global issue. However, Giddens sees that globalisation not only has an upward force but also offers the idea that globalisation also has the power to "push" down and "expand" to the sides.

With globalisation "pushing" downward, Giddens believes that globalisation must be understood as a force that pressures actors below the state level to be more active in international relations. Because the issue has been "pulled" upwards, the agency of these actors is at the same time under pressure to respond.

Finally, globalisation "extends" aside which means that it creates cultural and economic zones across borders. Giddens exemplifies Hong Kong, Northern Italy, and Silicon Valley. These regions, according to him, not only have functioned as constituents of the existing nation-state, but also are integrated with the surrounding regions with factors such as structure (regional organisation), history, and economy.

So, for Giddens, globalisation has given birth to what is called a global cosmopolitan society. These communities are slowly detaching themselves from the rigid national identities, and becoming more and more able to see themselves as a part of the broader global village.

Then, the classic literature on the impact of globalisation on international agencies was brought by Keohane and Nye (1977) which gave rise to the idea that one day the state will fade its role as an international actor. On the other hand, both said that other actors would 
emerge to fill the country's role, including multinational companies (MNCs) and nongovernmental organisations (NGOs).

Outside the group, there is a group located in the "gray area", which consist of subnational entities. They are referred to as the dwellers of this "gray areas" because, on the one hand, they are unlike MNCs or NGOs that are independent and have specific issues. On the other hand, subnational entities have a character that is structurally similar to the state but is essentially not the state because it only has partial control over the administration of the state. They are included in this group are subnational elements such as provinces, states, prefectures, and cities. The activities of these subnational elements are then through the writing of Ivo Duchacek (1984) in his article The International Dimension of Sub-National Self-Governments is called "paradiplomacy".

In his journal article, Duchacek (1984) coined the term paradiplomacy as an umbrella term for global and transregional diplomatic activities by subnational entities. Initially, "paradiplomacy" first appeared in an academic study by Rohan Butler (1961) in his article entitled Paradiplomacy. However, in its emergence, the term paradiplomacy is very different from what we know today. According to its conception, Butler considers paradiplomacy to be a "isolated" or "under the table" diplomacy, that is, informal diplomacy that runs behind real diplomacy. This interpretation is considered problematic because the first definition of paradiplomacy coined by Butler actually refers to what we know today as secret diplomacy. The emergence of the secret diplomacy phenomenon is not new, because it has existed since the emergence of the history of diplomacy and international relations. In fact, paradiplomacy - as understood as a new phenomenon of international relations - has a meaning which is completely different from that. Therefore, this definition was later rejected by reviewers of paradiplomacy that connected it with the new phenomenon of international relations. It is this Duchacek's definition that has been generally accepted.

After the end of the Cold War, the study of paradiplomacy has become more extensive. In the 2000s, a number of scientists who focused on the study of federalism and regional autonomy tried to further conceptualise paradiplomacy. Among these writers, there are Wolff (2007) and Cornago (2010). Wolff (2007) tries to answer Duchacek's (1984) anxiety by developing debate about paradiplomacy in a more optimistic direction. In Paradiplomacy: Scope, Opportunities, and Challenges, he argues that paradiplomacy should be seen as a positive opportunity rather than a threat.

Wolff (2007) concluded that paradiplomacy had shifted the classical logic from Westphalia-style sovereignty. He argues that the state can no longer ignore the interests of its region to have autonomy. On the contrary, the state must now be prepared to compromise by giving a certain amount of power to regions with specific characteristics in order to maintain its integrity. Thus, rejecting autonomy will be potentially counterproductive to the sustainability of these countries.

With a similar argument, Cornago (2010) also believes that paradiplomacy has now been "normalised" by no longer considered something foreign to international relations. 
Subnational diplomacy is evidence that there has been a transformation in interactions between countries globally. Cornago defines "normalisation" as "a mode of control that recognises previously foreign practices to be valid, by adding clear boundaries to these practices" (p.14). Its subnational entities began to be taken into account not only as implementing foreign policy provided by the state but also as active managers of their own foreign activities. Talking about this context, the city is included in it. At present, around 55 percent of the world community lives in cities (United Nations Department of Economic and Social Affairs 2018) and this number is expected to continue to increase as globalisation continues.

However, in studying paradiplomacy, it is important to look at the level of government studied because it will influence the logic used in analyzing paradiplomacy. Region level government, or one level below a country such as a province; States; and prefectures fall into the category of meso-level government with capacities that are above the city but below the country (Cornago 2010). In this case, paradiplomacy research at the regional level has a very colorful dimension because each country has its own policies regarding the transfer of power. The paradiplomatic capacity of Indonesian provinces such as East Java, for example, cannot be compared with the capacity of the government of the Republic of Tatarstan in Russia or autonomous regions such as Catalonia in Spain. As a result, a number of regional-level diplomacies also has different dimensions, according to its capacity and diplomatic agenda.

Through another article, Lecours (2008) argues that paradiplomacy is not a uniform process as there are several factors driving it. $\mathrm{He}$ conceptualises those factors as the "three layers of paradiplomacy", stating that there is no single explanation on paradiplomatic activities. Subnational regions may engage in foreign affairs driven by different "layers". First, Lecours says that at the very basic, there are pragmatic paradiplomacies which focuses only on economic gains. This is where the mainstream liberal explanation on paradiplomacy falls under. The economic layer is only concerned with taking part in the global economic competition. The economic paradiplomacy has no explicit political and cultural dimensions. At this level, there are objectives such as targeting new markets, attracting foreign investors, and luring multinational companies to enter.

Second, Lecours mentions the existence of a second layer, namely cooperation. In this case, the cooperation is defined as paradiplomacies which no longer only considers economic benefits, but also involves the exchange of knowledge. Lecours illustrates this level of paradiplomacy with examples such as (1) the Baden-Wurttemberg lander (a type of province) in Germany which was the pioneer in the formation of the Assembly of the European Regions and (2) the Rhone-Alpes region in France which has bilateral cooperations with a number of regions in foreign regions such as Africa, Asia, and Central Europe. The two partnerships, according to the concept of Lecours, contain elements such as development assistances, cultural and educational exchanges, as well as scientific and technical cooperations.

Finally, as also mentioned by there are paradiplomacies which rise due to the 
differences held between the subnational actors and their parent countries. In this category, there are regions such as Quebec, Flanders, Catalonia, and Basque. Paradiplomacies at this level do not aim to merely reap economic profits or increase cooperation, but to build diplomacies that emphasises the political autonomy they have.

Based upon those backgrounds, this paper attempts to shed a light upon a following questions: how do we make sense of the increasing paradiplomacy of cities in international affairs? This is particularly an intriguing question owing to the era wherein sub-state entities are now realising their agencies in globalisation.

In so doing, the author will utilise the theory of constructivism in finding an alternative toward the rationalist theories' explanations on the role of cities. This paper argues that using constructivism offers a wider explanation which goes beyond the profitoriented incentives offered by the connectivity within the globalisation itself. A constructivist approach sees that city paradiplomacies reflect the need of cities to be project their identites to the other international actors.

\section{Theoretical positions on paradiplomacy}

In analysing the role of cities in globalisation, the author shall explore the prevailing theoretical positions in regards to the topic of paradiplomacy.

Theoretically, there are three positions in the theory of International Relations in explaining the phenomenon of paradiplomacy. Kaminski (2018) in Paradiplomacy - Discourse Analysis and Research Conceptualisation believes that paradiplomacy is still difficult to become a popular object of study because it has many "faces", while there are still limited theories to explain the phenomenon. He also offers three major theories of International Relations: realism, liberalism, and constructivism in explaining it.

Realism, as a state-centric theory, tends to say that paradiplomacy is nothing more than the intervention of the central government to play its role more at the regional level. Realism considers that the state-centric system is still not obsolete and will continue to be relevant to be used to explain the phenomenon of regional government cooperation at the global level (p.19).

Liberalism, on the other hand, sees that paradiplomacy is the result of changing trends in international relations. Liberals believe that the state is no longer the most important actor in global politics. Paradiplomacy then appears to emphasise the boundaries between high politics and low politics, including the relationship of democratisation to the ties of loyalty between the regions and the center (p.19). Regional cooperation, for a liberalist perspective, is an opportunity for subnational actors to gain profits and establish interdependence in the era of globalisation. The proponent of this theory is Keohane and Nye (1977) with their idea that globalisation has transformed relations between countries into something more complex (complex interdependence) by also involving elements of the wider society as actors. This theory sees paradiplomacy as a reflection of international relations which is no longer only focused on political and security issues, but also issues that have been considered peripheral 
such as the economy and the environment.

Third, constructivism sees paradiplomacy as the result of intersubjectivity that forms interstate relations. Wendt (1992) is the pioneer of this theory, which says that the position of international actors in the world is not deterministic; it is determined by social constructions that are formed based on their interactions with other actors on earth. So, different from the two previous perspectives, it is more bottom-up in looking at international actor agencies. Paradiplomacy in this respect is seen as an effort by subnational actors to build their own identities. Meanwhile, this identity consists of a variety of spectrums ranging from maintaining the image of the region through culture to preparing the area concerned to free themselves. This constructivism perspective is very useful to then be used to study how the foreign relations of a region are used to build political autonomy that is different from the country of origin, but it is also useful to see how perceptions of regional elites towards paradiplomacy activities carried out by their regions - whether harmonious or contrary to the perspective of the state its parent. Constructivism rejects the notion that paradiplomacy is only an extension of the state's interests, as is the realist assumption, or a direct response to interdependence and globalisation, as is the assumption of the liberals.

In the study of International Relations, constructivism is considered a big theory that falls within "the middle ground". Rather than assuming that state behavior is derived from human behavior that is instinctive and deterministic, as is the assumption of classical realism and liberalism, it upholds an assumption that international politics is a social construction. Constructivism can be considered a "cultural theory" in International Relations because it criticises the approaches of previous theories that are too positivistic by emphasizing the material aspects of studying a state, such as through its economic and military forces.

Constructivism is a theory which says that the position of international actors in the world cannot be generalised, as it is determined by social constructions that are formed based on their interactions with other actors in the world. Fierke (in Dunne et al 2013, p.188) states that every object that is present in nature does not directly have a definitive meaning until it is given context. Even so is the case with international politics. It is planted by social values, norms, and assumptions rather than a product formed by mere structure. In this case, constructivism believes in the ability of agencies for countries to create their own identities in an anarchic global world.

Constructivism was developed by Berger and Luckmann (1966) through their conception of "social constructionism". The core of this concept is subject interactions in social relations forming a reciprocal pattern which then determines future social actions. Society, for Berger and Luckmann, is a reality that can be both objective and subjective. Social reality is objective, seen from human interactions which then turn into a separate pattern. The pattern is then institutionalised so that eventually it becomes a reality that is seen as objective knowledge. On the other hand, it is also a subjective reality because it includes the process of socialisation and the creation of an 
identity that is formed not only from within but also from the social space in which individuals interact.

The debate about constructivism in International Relations first began by Nicholas Onuf (1989) in The World of Our Making which argues that in essence, the state is indeed anthropomorphic (like humans), taking a little idea from the realist and liberalist theories. However, he thinks that the life we live in is a "world we have created" with what we know to be "social facts" that are actually shaped by our own activities. Onuf's work seems to overhaul the perspective of the study of International Relations by positioning the state no longer as a unitarian unit, as we view humans as a whole person. The state, according to Onuf, is nothing but a social organisation whose reality needs to be explained more deeply. Arguing with previous views about realism and liberalism, which tends to be structuralist, constructivism offers that the behavior of international actors is not only shaped by anarchist structures, but by intersubjective interactions between the two. The institutionalisation of relations and the rules of the game are formed on "constructions" based on interactions between actors. He rejects the idea that "anarchy" is deterministic. Instead, "anarchy" is a product of social interaction which then gives rise to a shared understanding of such conditions.

However, as a "middle ground" theory, constructivism also adopts a number of thoughts regarding structure and agency. This theory is also influenced by Giddens's idea of structuration and integration between agent-structures in international politics. Using criticism of Marxism to construct his own theory, Giddens writes that agents and structures cannot be separated from each other. According to Giddens, all social actions involve structures, and all structures involve social actions (Ritzer and Goodman 2008). Constructivism believes that both agents and structures can influence each other, or mutually constituting. This is, of course, different from how positivistic theories such as realism and liberalism view that under the structure, agents will have deterministic patterns of interaction.

The hallmark of a constructivist perspective is its emphasis on intersubjectivity. This theory speaks in a broader theme than just the structure and influence on the behavior of international political actors. Referring to the concept of relationality (Riyanto 2018), the discussion on intersubjectivity can be found from the concept of "me" as a subject in its interaction with "phenomena" and "others" which are interrelated. Constructivism treats these actors as subjects who have an "I" consciousness that contains aspects of "depth, involvement, existence, and existence" in the face of certain experiences (p.189). In this case, he builds a foundation of thought for the agency of international political actors in an anarchist global structure. In this case, the intersubjectivity between "me" and "other" is illustrated in a hypothetical condition between two alien figures named Alter and Ego who do not know each other. The behavior of the two is then determined based on the signals sent by each other. The signal is obtained in the form of historical interactions which then uniquely establish an identity between the two (Wendt 1992, pp. 404-5). This concept is called symbolic interactionalism (symbolic 
interactionalism). This illustration is also used to refute deterministic concepts stating that anarchy tends to make an international actor behave antagonistically and does not have trust (realism) or cooperation and is subject to the rules of the global institutional play (liberalism).

The position of constructivism in viewing reality can be concluded to be influenced by Freud's psychoanalysis. This was demonstrated by Buekens (2006) by dismantling the hermeneutical process of psychoanalysis and its relation to social constructivism. He mentioned that the objects in the world in the pattern $\mathrm{X}$ are $\mathrm{Y}$, where " $\mathrm{X}$ " is the object to be observed, while "Y" is a psychoanalytic concept which came to be known as institutional facts. As long as $\mathrm{Y}$ has an agreement that $\mathrm{Y}$ is understood properly by the general public, then the existence of $\mathrm{Y}$ as an institutional fact will continue to exist. Boudry (2008) also said that social facts are basically a collection of facts that form a system of interactions. More or less, that's how "reality" in international relations was created. In their interactions, each actor is always in an effort to establish meaning for themselves, both in a position of amity or enmity.

Wendt (1999) in the Social Theory of International Politics helped enrich the treasure of the concept of "I" and "other". In formulating his theory, Wendt was inspired by scientists such as Hobbes, Locke, and Kant. The three scientists encouraged Wendt to develop the concept of "three cultures of anarchy" which encapsulated the behavior of political units within anarchy. First, Wendt said there was a culture of enmity that descends from the Hobbesian philosophy. In Leviathan (1651), Hobbes described the human condition without a social contract as bellum onmium contra omnes (war between all against all). Wendt interprets the condition without the social contract (state of nature) into a relationship between "I" and "other" as conflictual. In this hostile culture, the "I" is an actor who does not recognise the subject's "other" right to exist. As there is no trust, "I" has no reason to to limit its aggressive behavior, turning enmity as a necessary and legitimate norm. The second pattern of culture is known as the culture of rivalry, derived from the Lockean philosophy. Within this culture, coercion may persist but it is limited by an acknowledgement that the "others" have their own right to exist. Therefore, sovereignty is a norm shared among the existing actors under anarchy, limiting violence behaviours. Lastly, there is the culture of amity, coming from the Kantian philosophy on perpetual peace. Based upon this culture, the entities under anarchy use friendship as the basis of interaction. As the consequence of this culture, conflicts are settled without violence, as the "I" and the "other" share the belief that interactions under anarchy should be based upon the pursuit of common gains (Wendt 1999, p.260).

For constructivists, paradiplomacy is mainly concerned with how an international entity "signals" its existence to the other actors in the world, in expectation that the other actors may reciprocate by recognising the respective entity as an autonomous political being. A notable effort to incorporate constructivist elements in the study of paradiplomacy can be seen through the work of Sharafutdinova (2003). Using the case study of the Tatarstan region in her native Russia, she sheds a light 
on the topic of identity construction in the paradiplomatic activities. In light of this discussion, Sharafutdinova (2003) notes that:

“...foreign activities might constitute politics of representing a region in a certain image and could be an essential part of the identity construction project, through which the regional government attempts to incorporate elements of sovereign statehood in the regional identity." (p.616)

\section{Cities in the discourse of paradiplomacy}

Cities have a slightly different paradiplomatic logic compared to regions that are positioned directly below the state authority, such as provinces and constituent states. In most cases, the internationalisation of city activities has never been seen as a threat to the integrity of the state. Cities are not considered as part of state power but as a symbol of public power. Paradiplomacy by cities is generally more the product of decentralised international relations with rules that are residues from international relations between countries. The logical differences between regions and cities were also highlighted by Van Der Pluijm and Jan Mellisen (2007). In the paradiplomacy of regions, there is a potentially contradictory relationship due to the conflict of control over the same area. On the other hand, in the case of urban paradiplomacy, relations tend to be complementary because city paradiplomacy is generally a remnant of international affairs that are not regulated by law. However, that does not mean the topic of urban paradiplomacy is not problematic. In the case of cities, interests tend to arise because the state does not accommodate local interests. City paradiplomacy emerged as a global interdependence response, so that the public, through the city, began to be considered as actors who lived the course of international politics. The city is also "filling the gap" left by the state to advance its own interests.

With the accumulation of capital and information located in urban areas, we can no longer ignore the crucial role of cities in international relations. Some authors have confirmed that the shift in focus towards urban areas is a new trend in International Relations (Barber 2013; Curtis 2016; Khanna 2016; Kangas 2017; Herrschel and Newman 2017). In his book, writers such as Barber (2013) and Khanna (2016) explain that in the future, cities are political units that have great significance, and even tend to replace countries as players in globalisation. Barber (2013) based his thesis through the argument that globalisation gave rise to what was called the "crisis of the nationstate". Countries recognise their inability to manage increasingly complex global issues. Barber also argued that what then happened was the rise of cities to the surface of international politics. Barber called the city "the original incubator of democracy" because at first, cities were the early forms of polity prior to the era of empires and the nation-states. Thus, the future of international relations is in the world's urban networks that are connected on the basis of collaboration, creativity, pragmatism, and multiculturalism. The locality of the city also makes it closer to the actual issues that exist in the community, so that the city is better able to respond accurately to any matters that need to be resolved immediately. However, the classic problem that occurs is that cities in the 
contemporary era are not policies that we have known in the past. At present, cities do not have sovereignty but are under the jurisdiction of the nation-state that houses them. In a similar vein, Khanna (2016) also mentioned that in the future, civilisation will be far more connected with the city as its points (hubs). National borders will be replaced by a "connectography" consisting of connections between one place and another. With the increasing flow of urbanisation, the emergence of global cities (such as "alpha" and "beta" cities) can be counted as a future that will divert our attention from the superpowers.

However, analyzing such phenomenon through the liberal lens alone can be misleading, as it tends to assume that all cities respond universally to the phenomenon of globalisation. Yet, it is too careless to say that every city is moving at the same pace, thus having the same response towards the concept of the "global city". Each city has a different exposure to globalisation, which makes it has the experience that is different from one another.

Criticism of urban globalisation as a uniform process can be seen through the works of Robinson (2002) and Shatkin (2005). The former objects to the tendency that there has been too much emphasis on "globally functioning" cities such as New York and London to conceptualise the globalizing process of world cities. She criticises such approach as “imperialist” (p.532). Therefore, a restructured, decolonised, approach in theorizing urban space should be introduced to the mainstream.

Under the same approach, Shatkin also criticises the common approach toward the concept of global cities that assumes that each city is uniform in the face of globalisation.
He points out that there are three points that highlight the main problem in such assumption. First, he stipulates that there has been a problem with social inequality, in which there have been deep polarisations between the wealthy and the impoverished. Next, there are also uneven developments, particularly when the polarisation between the haves and the havenots has become embedded through spatial segregations. Lastly, political inequalities also occur when there is a noticeable gap between the interests of the policymakers and the interests of the common dwellers (p.2).

An exploratory study by Zelinsky (1991) has long warned us that urban paradiplomacy is not void of identity considerations. His study opens a perspective to understand that the behaviour of cities in making relations with the other overseas counterparts does not come from a vacuum. There have been factors taking roles such as historical connections, shared ideational concerns, and similar cultural attractions. His findings indicate several generalisations. First, city twinnings will less likely to occur among cities under states which still hold traditional enmities, signaling the initial process of knowing their "alter and ego" positions under the international realm. Second, cultural considerations also come into play, where cities possessing more cultural similarities may engage in paradiplomacy compared to those who do not. Third, political ideologies can also be a driving force in how cities pick their partners.

\footnotetext{
"The level and pattern of these transnational twinnings are shaped, to a noticeable degree, by propinquity
} 
and/or compass direction, historical and cultural legacies, and the diplomatic and commercial policies of the national regimes in question. [...] it can be a double-edged instrument since a growing number of twinnings seek to promote social ideals that transcend national borders and/or constitute controversial enterprises that challenge statist interests and are a rebuke to the idea of the unbridled sovereignty and omnipotence of nation-states." (p.28)

Those explanations can us that within the gap between the domestic context and the international realm. While the author agrees with a part of the liberalist notion that paradiplomatic activity is a response to globalisation, using it blindly will only put us under a simplification trap that paradiplomacy activities do not consider the elements of identity. A liberalist approach to paradiplomacy is a useful tool to explain the interconectedness of global economy, yet it cannot fully capture the dynamics of how cities societies experience globalisation and respond it in their own ways. When city paradiplomacies are taken for granted as mere economic response to globalisation, we are more likely to fail in viewing cities as subjects with possible agency awareness in international politics. One of its consequences is something which Tavares (2016) coins as the "ceremonial paradiplomacy". This concept refers to paradiplomacy which is merely pursuing legal documents without any follow-up at the relevant location. He mentions that this is a common symptom in developing Asian cities, where paradiplomacy is losing its essence due to its failure to capture what the cities really need (p.31).

\section{Looking beyond trade: The Case of Barcelona}

Barcelona serves as a perfect illustration on how city paradiplomacies are built upon local values and historical legacies. The foreign affairs of this Spanish city demonstrates how the collision between the local identities and cosmopolitan values has created a unique pattern of paradiplomacy which goes beyond trade as the main driver.

The democratisation of Spain has considerably become a moment which paved the way for Barcelona to be an active city in international relations. It was started by the creation of the 1978 National Constitution following the death of the dictator Francisco Franco. The result of this new constitution was the creation of 17 autonomous communities and 2 autonomous cities. Among those autonomous communities, there are 3 communities labelled as the "historic nationality", reacknowledging the distinctive identities held by those communities which was initially discouraged by the dictatorial regime which had favoured centralism and uniformity for all of the Spanish regions. Those communities are Galicia, Basque, and Catalonia. The latter is the autonomous community in which the city of Barcelona is located. Consequently, this new constitution has been a upward force for those initially marginalised historic nationalities to become even more active in rekindling their identities. Barcelona is no stranger to this pulling force. As the capital city of Barcelona, the city has been using its recently acquired status as the capital of the new autonomous region to signal its existence to the international forum. 
Zamorano and Morato (2015) see that the activity of Barcelona relates to the creation of external image following the democratisation of Spain. The emergence of Catalonia as an international actor depicts the multi-layered nature of the Spanish decentralisation. In the wake of the ascension of the 1978 National Constitution, Barcelona officials envisioned their cities to be an internationally active city based upon cultural paradiplomacy. The preparation began led by Mayor Pasqual Maragall from the Socialist Party of Catalonia by creating an urban space development which was based upon "a civic discourse that manifested specific representations of Barcelona's personality" (p.15). His efforts highly emphasised the importance of local culture as the key elements of urban developments. One of the steps being done was the public funding to revitalise the heritage buildings and developing new projects in order to polish the aesthetics of the city.

The movements to catapult Barcelona into global presence were also spurred by the prospect of hosting the 1992 Olympics. In preparation of the aforementoined event, Barcelona created an institution called the City's Council's International Relations Department. The institution acts as an office to regulate the international affairs of the city. There were three prioritised regions: Europe, Latin America, and the Mediterranean. The institution acts as an equal to the Ministry of Foreign Affairs in the case of sovereign states. The city council used the moment of Olympics to agressively promote the Barcelona identity through events such as Cultural Olympiad (1987), Year of Sport (1989), Year of the Arts (1990), Year of the Future (1991), and the Olympic Festivals of the Arts (1992) (Moragas i Spa in Zamorano and Morato 2015, p.6).

After the Olympics was successfully held in Barcelona, the city increased its international presence by focusing even more on cultural revival as the main theme of its paradiplomacy. For instance, Barcelona created Barcelona Institute of Culture (ICUB) as an diplomatic agency which manage various offices related to the city's cultural affairs. The aims of the ICUB are revitalising and internasionalising Barcelona's culture. ICUB has contributed in promoting cultural activities within an outside Barcelona, like managing the Plato Film Commision in 1996 which aims to promote the local films. Balibrea (2005) likens the Plato Film Commision to a "tool of propaganda" in the sense that it has helped Barcelona diffuse and naturalise the image of its urban space (in Zamorano and Morato 2015, p.7).

Through the constructivist perspective, the paradiplomatic activities conducted by Barcelona has been characterised mainly by the constant signaling of its new identity following the regime change in its host country. Barcelona realises that its main peculiarity lies within its multifaceted identity. First, it reflects the clash between Spanish centralism vis-a-vis Catalan struggle for autonomy. On the other hand, it is also positioned in the middle of a conflict between cosmopolitanism vis-a-vis localism. Paradiplomacy, in this case, is a road taken by Barcelona to transform those conflicting identities into a new behaviour in international affairs. Those disputes have played a role in the city's redefinition as an active actor in globalisation.

Furthermore, McNeill (2001) argues 
that the paradiplomacy of Barcelona displays an effort to reinvent itself as a political space. Borrowing his perspective from political geography, he describes that Barcelona incorporates the "myth of Catalonia" as a basis of foreign relationships. This myth begins with a view of Catalan as a cosmopolitan-minded place after the Spanish turn to democracy paved a way to build such narrative. For Mayor Maragall, Barcelona can reinforce this myth by reinventing the city as the "cultural, political, economic, and intelectual"core of Catalan. This was exactly done by Maragall in envisioning his city.

We can also borrow MacLeod's (1998) conception about institutional formation in explaining the paradiplomatic behaviour of Barcelona. The international affairs of Barcelona can be understood as an action to serve as a collective "space-sensitive consciousness" which may go beyond the one possessed by the central government (MacLeod 1998, p.840). Therefore, cities need to be understood as not merely administrative entities which serve as the continuation of the central government, but rather as identity-aware entities like sovereign states which might possess ethno-histories characteristics. This notion can be found from how Maragall prioritised his paradiplomacy upon two things: (1) the physical appearance of Barcelona as the means to build the sense of space-counsciousness and (2) normalisation and institutionalisation of cultural diplomacies based on the reinvented Catalan struggle for autonomy.

The case of Barcelona paradiplomacy shows us that culture and identity can be a factor which explains the emergence of agency awareness of a certain city. Constructivism offers us a better in-depth perspective in viewing the nuanced motives of paradiplomacy, which otherwise cannot be sufficiently explained by liberalism with its tendency to put identity considerations aside.

The author argues that a constructivist lens does not only serve as a way of viewing paradiplomatic activities more deeply, but also as an approach to conduct the activities themselves. To shift city paradiplomacy to a more constructivist paradigm, the city government should not only adopt a top-down approach in carrying out foreign relations. When economic competition and globalization are the sole aims, the dimension of identity is dismissed and there is a tendency that people could be left behind among the elitist decision making process. To realise a paradiplomacy activity that is more aware of the identity of the city, the city government needs to collaborate with epistemic communities such as research institutes, universities, until the artist community so that an accurate projection of how the city is in globalization. This is in line with the idea of Risse-Kappen (1994) that the existence of foreign policy must be supported by a coalition of domestic people, because an idea does not float freely in a society (p.187). The process of "signaling" should include how the community perceives their city's identity. This can be done by the future research agenda which include focus group discussions, indepth interviews, and surveys on the perception of the city branding.

\section{Conclusion}

Concluding this paper, the author 
argues that paradiplomacy should not only be seen as a pragmatic response to globalisation but also a mechanism for recognising city identity through intersubjective relationships with other major cities in the world. In this case, nuances and variations will naturally emerge which make the description of paradiplomacy richer.

By adding a constructivism perspective toward the prevailing liberalist notion that paradiplomacy is a response to globalisation, the studies on paradiplomacy will become increasingly impactful.

First, it will hopefully enrich the academic realm by highlighting another facet of the existing debate. Second, it can also provide some input to the practitioners of paradiplomacy to better consider their background and position in globalisation before engaging in foreign activities. This may result in better coordination and better programs which can benefit the constituents in the long run.

\section{References}

\section{$\underline{\text { Books }}$}

Barber, B.R. (2013). If mayors ruled the world: Dysfunctional nations, rising cities. New Haven: Yale University Press. Berger, P.L. and Luckmann, T. (1991). The social construction of reality: A treatise in the sociology of knowledge. London: Penguin Books.

Boudry, M. (2008). What Social Constructivism Ought to Tell Us About Psychoanalysis (And What This Would Reveal About Itself). Ghent: Ghent University.
Buekens, F. (2006). Freuds Vergissing. De illusies van de psychoanalyse. Leuven: Van Halewyck.

Fierke, K.M. (2013). "Constructivism"e in Dunne, T. et.al. (eds). International Relations Theories: Discipline and Diversity. Oxford: Oxford University Press.

Giddens, A. (2002). Runaway world: How globalization is reshaping our lives. New York: Taylor \& Francis.

Kamiński, T. (2018). ParadiplomacyDiscourse Analysis and Research Conceptualization. In Pietrasiak, M et.al. Paradiplomacy in Asia. Lodz: Wydawnictwo Uniwersytetu Łódzkiego.

Keohane, R.O. and Nye, J.S. (1977). Power and interdependence. London: Longman

Khanna, P. (2016). Connectography: Mapping the future of global civilization. New York: Random House.

Kuznetsov, A.S. (2014). Theory and practice of paradiplomacy: Subnational governments in international affairs. London: Routledge.

Onuf, N.G. (1989). World of our making: rules and rule in social theory and international relations. London: Routledge.

Riyanto, E.A. (2018). Relasionalitas: Filsafat Fondasi Interpretasi Aku, Teks, Liyan, Fenomen. Yogyakarta: Penerbit Kanisius.

Schiavon, J.A. (2018). Comparative Paradiplomacy. London: Routledge. 
Tavares, R. (2016). Paradiplomacy: Cities and states as global players. Oxford: Oxford University Press.

Van der Pluijm, R. and Melissen, J. (2007). City diplomacy: the expanding role of cities in international politics. The Hague: Netherlands Institute of International Relations' Clingendael'.

Wendt, A. (1999). Social theory of international politics. Cambridge: Cambridge University Press.

\section{Journal Article (retrieved online, with DOI)}

Herrschel, T. and Newman, P. (2017). Cities as international actors. London: Springer. doi, 10, pp.978-1.

\section{Journal Article (retrieved online, without} DOI or page numbers)

Bell, D. (1989). 'The world and the United States in 2013'. Daedalus, 116(3), $1-31$.

Cornago, N. (2010). On the normalization of sub-state diplomacy. The Hague Journal of Diplomacy, 5(1-2), pp.11-36.

Curtis, S. (2016). Cities and global governance: State failure or a new global order?. Millennium, 44(3), pp.455-477.

Duchacek, I.D. (1984). The international dimension of subnational selfgovernment. Publius: the journal of federalism, 14(4), pp.5-31.

Kangas, A. (2017). Global cities, international relations and the fabrication of the world. Global Society, 31(4), pp.531-550.
MacLeod, G., 1998. In what sense a region? Place hybridity, symbolic shape, and institutional formation in (post-) modern Scotland. Political geography, 17(7), pp.833-863.

McNeill, D. (2001). Barcelona as imagined community: Pasqual Maragall's spaces of engagement. Transactions of the Institute of British Geographers, 26(3), 340-352.

Risse-Kappen, T. (1994). Ideas do not float freely: transnational coalitions, domestic structures, and the end of the cold war. International organization, 48(2), pp.185-214.

Robinson, J. (2002). Global and world cities: a view from off the map. International journal of urban and regional research, 26(3), pp.531-554.

Sharafutdinova, G. (2003). Paradiplomacy in the Russian regions: Tatarstan's search for statehood. Europe-Asia Studies, 55(4), pp.613-629.

Shatkin, G. (2007). Global cities of the South: Emerging perspectives on growth and inequality. Cities, 24(1), pp.115.

Terre Blanche, M., dan Durrheim, K. (1999). Histories of the present: Social science research in context. Research in practice: Applied methods for the social sciences, 2 , pp.1-17.

Wolff, S. (2007). Paradiplomacy: scope, opportunities and challenges. The Bologna Center Journal of International Affairs, 10(1), pp.141-150. 
Zelinsky, W. (1991). The twinning of the world: sister cities in geographic and historical perspective. Annals of the Association of American Geographers, 81(1), pp.1-31.

\section{Working Paper}

Lecours, A. (2008). Political issues of paradiplomacy: lessons from the developed world. Discussion Papers in Diplomacy. The Hague: Netherlands Institute of International Relations Clingendael. pp 1-15

\section{Electronic sources}

Hobbes, T., (1651). Leviathan. Retreived from https:/www.ttu.ee/public/m/ mart-murdvee/EconPsy/6/Hobbes Thomas_1660_The_Leviathan.pdf

United Nations Department of Economic and Social Affairs. (2018). 2018 Revision of World Urbanization Prospects. Retrived from https:// www.un.org/development/desa/ publications/2018-revision-ofworld-urbanization-prospects.html 